\title{
Martina Baleva \\ The Photographic Portrait of Georgi Benkovski, or the De-Archiving of the National Hero ${ }^{1}$
}

[I]n our modern cultural life, the establishment of the corporeal personality, of the undeniable identity of an adult, corresponds to the most widely varied needs.

Raymond de Ryckère ${ }^{2}$

The photographic portrait of Georgi Benkovski, one of the emblematic figures in the Bulgarian national liberation movement, is among the most well-known in the portrait gallery of the great national heroes of that country. Only initiates are granted a look at the unremarkable, poorly preserved carte de visite portrait that holds the status of a national relic in the photo archive of the National Library in Sofia. ${ }^{3}$ At the same time, it has been reproduced hundreds of times - in scholarly and popular literature, in illustrated encyclopaedias, anniversary publications and school textbooks. Its reproductions are exhibited in museums, it decorates public buildings and offices, schools and universities, book covers and commemorative plaques, and it frequently finds its way into the mass media. In the Bulgarian and English-language Wikipedia entries on Benkovski's biography, the prominent likeness crowns the hero's birth and death dates. ${ }^{4}$

The portrait began its career in 1907, when it was first reproduced as a wood engraving by the historian Dimitar Strashimirov in his three-volume history of the Bulgarian uprising of $1876 .{ }^{5}$ Half a century after this first publication, a discussion of a kind unique in the history of Bulgarian imagery flared up over the identity of the

1 This essay first appeared in an abridged version in Bulgarian: Baleva 2012.

2 Quoted in Bertillon 1895, p. LXXV.

3 Despite repeated official requests, I was ultimately able to inspect the original photograph only by a circuitous route.

4 Georgi Benkovski (c. 1840-1876), whose real name was Gavril Gruev Hlatev, was among the leading members of the group of radical Bulgarian exiles to Romania who, from their base in Bucharest, organised and led the brutally suppressed 1876 April Uprising against the Ottoman government. An initial attempt at a Bulgarian revolt had been undertaken in the autumn of 1875, in the context of which Hlatev had been entrusted with the task of setting fires at strategic locations in the Ottoman capital. The revolt failed, as did Hlatev's role in it. As a result, he fled to Romania with the forged passport of a Pole by the name of Antoni Benkovski. During the April Uprising of 1876, Hlatev - now known as Benkovski - led a group of rebels who went down in the nation's history as the "Flying Squad." Just a few days after the outbreak of the uprising in the heart of the empire, Benkovski and many of his comrades were captured and killed by government troops. On the name change, see below.

5 Strashimirov 1907, vol. 1, after p. 236. 
portrait's subject, and thus over its 'authenticity.' The debate was soon to be stifled, however, in the pathos of Communist historical patriotism. It was carried out primarily between the author Anna Kamenova and the historian of Bulgarian photography Hristo Jonkov. Two decades after this initial polemic, the painter Zhechko Popov likewise adopted a stance on the matter, bringing the dispute to an end - at least for the time being - in favour of the advocates of the 'authentic' portrait.

I would like to take this discussion as a point of departure and an opportunity to examine the relationship between historical photography and its archiving in the service of the nation. In the process, I will summarise the main arguments of the two sides of the discussion as a basis for developing a number of issues that have never yet undergone investigation with regard to "the establishment of the corporeal personality, of the undeniable identity" 6 of the photographed person. The various archival layers that have come to be superimposed on the photograph, and in a sense to lend it identity, will be revealed one by one as a means of reconstructing the photo's career a very adventurous one at times - from simple carte de visite portrait to the status of national icon. In other words, I will endeavour to 'de-archive' the image of the hero.

The inspection of the portrait's so-called 'authenticity' and its 'de-archiving' are not an end unto themselves. I am taking them as an occasion to clarify the mechanisms by which visual (national) identity is generated through photographic archives. The case study will thus provide insights into the lengthy process of photo-archival practice within the Bulgarian national discourse, an overwhelmingly complex process distinguished in part by contradictions and caprice. After all, this case is eloquent testimony to the treatment of photographic sources and to the nation's unquenchable thirst for photographic images.

\section{The Dispute}

It was on the occasion of the eightieth anniversary of the April Uprising of 1876 that Anna Kamenova, the great niece of Gavril Hlatev, alias Georgi Benkovski, first published her doubts about the authenticity of the portrait of her kinsman and the leading revolutionary of the Bulgarian national movement in the weekly Literaturen front ("Literary front") (fig. 1). According to Kamenova, who describes at first a bust portrait of Benkovski, "this calm man [...], gazing out of the picture indifferently [...], with black eyes, black hair, sleek, reddish skin [...], a small black moustache, of medium height, rather plump, with an absent and vacant gaze" could not be Benkovski. ${ }^{7}$ To support her line of reasoning, Kamenova cites the comparison of the available pictorial material with contemporary descriptions of Benkovski in written sources. As

6 Bertillon 1895, p. LXXV.

7 Kamenova 1956, front page. 
is apparent from the text quoted, she subjects the visual material to very free interpretation, without basing it on formal analysis or comparing it with any contemporary artistic practices that would permit the deduction of objective criteria for assessing psychological characteristics such as the portrait subject's facial expression or intellectual capacities. It is, moreover, problematic to determine the "height" of a person on the basis of a bust portrait.

Then Kamenova compares the qualities of the image she has thus described with descriptions of Benkovski's appearance in written sources such as Zahari Stoyanov's famous Memoirs or the less well-known Memories of Michail Madzharov. ${ }^{8}$ According to Kamenova, both authors could vouch for the truth because they were "eyewitnesses who knew Benkovski very well." They described their comrade as "tall, slender, blond, with light eyes, a long, blond [...] moustache, his fingers - long, his gaze - sharp." In view of the juxtaposition of the portrait bust's characteristics with those from the written descriptions - "black eyes" vs. "light eyes," "black hair” vs. "blond hair," "small black moustache" vs. "long blond moustache," "squat” vs. "tall," "plump” vs. "slender" - any doubts about the portrait's 'non-authenticity' seem to be out of the question. From the comparison of the diametrically opposed characteristics, the author comes to the conclusion that "there can be no doubt that the widely disseminated portrait of the black-eyed man is not of Benkovski."10

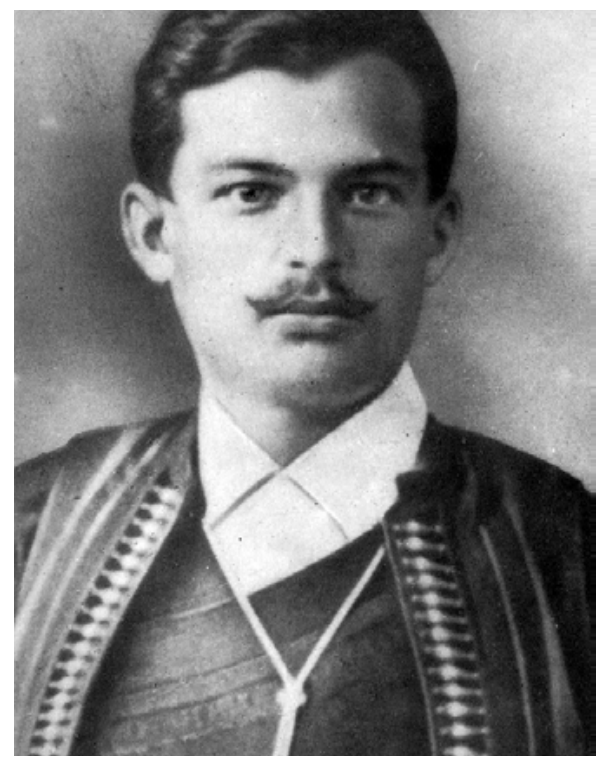

Fig. 1: Dragan Iliev: Georgi Benkovski, 1902. Technique, dimensions and whereabouts unknown. Photomechanical reproduction from: Anna Kamenova, “Obrazat na Benkovski,” in: Literaturen front, 18, 3 May 1956.

8 Stoyanov 1933; Madzharov 1968.

9 Kamenova 1956, front page.

10 Ibid., my italics. 
On the basis of this assessment, Kamenova subsequently raises the question as to how and why, despite these contradictions, it came about that the portrait was considered to be one of Benkovski. To answer this question, she now resorts to the reminiscences of her father, Michail Madzharov, Benkovski's nephew and the son of one of his sisters. Here I will quote the passage in its entirety since it contains interesting information that contributes to clarifying the question of the portrait's 'authenticity' and also provides insight into the early practices of photo archiving in Bulgaria around the turn of the century.

On the occasion of the twenty-fifth anniversary of the April Uprising (1901), the committee in Sofia and Panagyurishte entrusted with the festivities had to obtain portraits of all of the famous revolutionaries who led the uprising. There were portraits of [Panayot] Volov, [Todor] Kableshkov, and Nayden P. Stoyanov. Only the portrait of Benkovski was missing. The members of the committee remembered that Benkovski had been a tailor in Eski Şehir for a time, and had worked in partnership with a man from Panagyurishte. This partner was believed to have been married to a Greek woman and to have died after the liberation [of Bulgaria from Ottoman rule in 1878]. A letter was written to the wife in Eski Şehir with the request that she send a photo of her husband's partner, if such a photo existed. The Greek woman will hardly have been capable of understanding the committee's letter, which was written in Bulgarian! [...] She then really did send a photo, not of Benkovski, however, but of her departed husband. Without thinking, the committee took the photo to be authentic. And that is the picture that today is circulated as a portrait of Benkovski. ${ }^{11}$

According to the passage, the portrait had a completely banal misunderstanding to thank for its initial circulation.

Yet Kamenova also discusses another portrait, now a full-length one (fig. 2), which she claims

is of Benkovski, in which, however, he is much younger, taken in Istanbul when he first travelled abroad. In it, Benkovski is seen with a fez, light eyes, a blond moustache, tall, slender, with a spirited face. In view of the family resemblance it could be assumed that this is the likeness of the young Gavril Hlatev. ${ }^{12}$

In this portrait (fig. 2), in addition to the "family resemblance," Kamenova identifies all of the outward features that correspond to the written sources and at the same time contrast with the characteristics of the portrait bust she has described (fig. 1).

11 Ibid. Michail Madzharov (1854-1944), a prominent Bulgarian politician, diplomat and commentator and alumnus of the prestigious American Robert College in Istanbul, began compiling his famous Memories in the first decade of the twentieth century; he committed them to paper between 1939 and 1942. In the second edition of the Memories published in 1968, the publisher, Vesselin Andreev confirms Kamenova's account "that Benkovski's portrait [...] is actually that of his partner Hrelkov in Eski Şehir”: Madzharov 1968, p. 762.

12 Kamenova 1956, front page. 


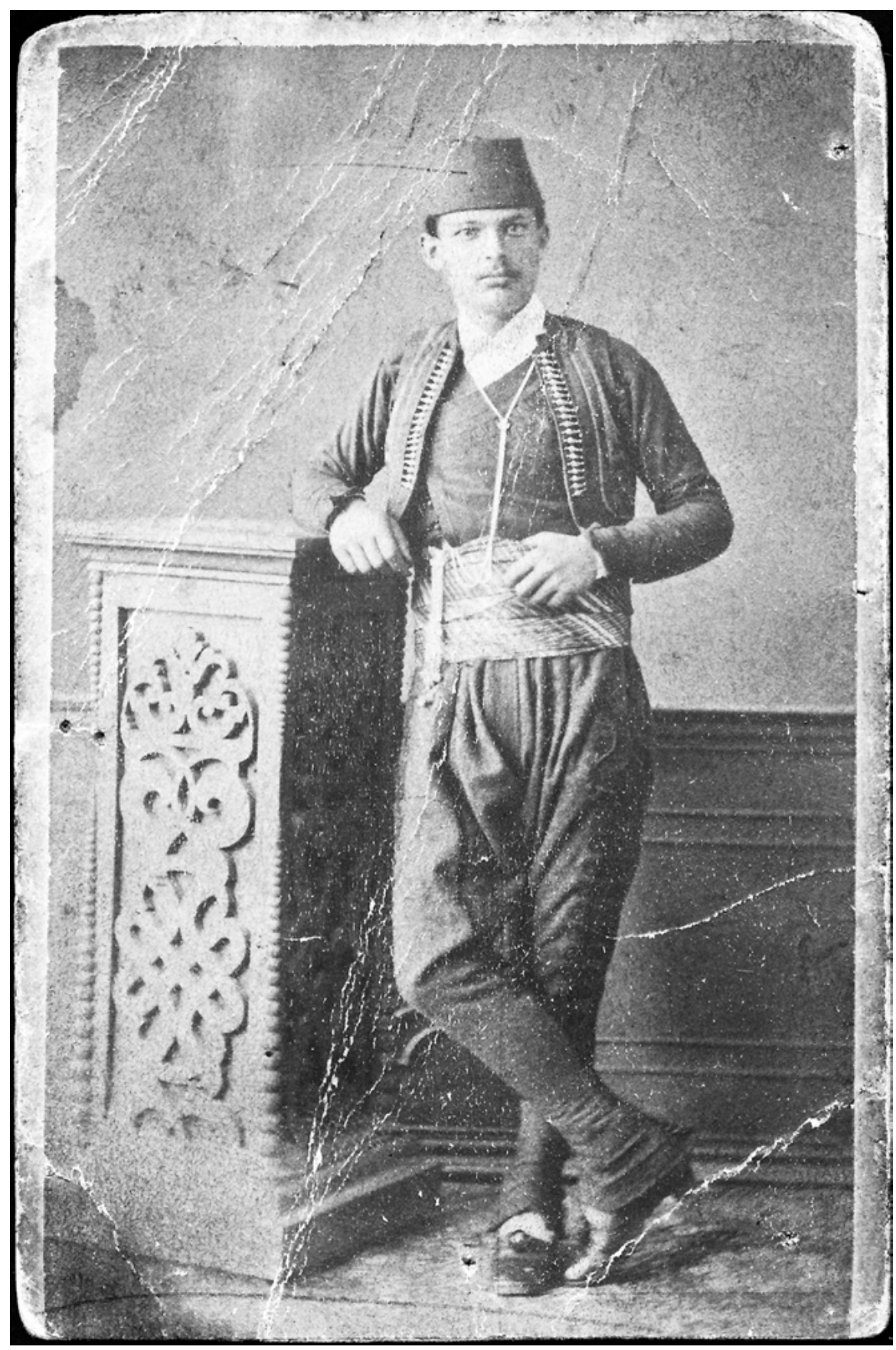

Fig. 2: Pascal Sebah: Anonymous photo portrait of an Ottoman intellectual. Albumen print, calling card format, front, Istanbul after 1874. Mounting board: $6.3 \times 9.6 \mathrm{~cm}$, photograph: $5.3 \times 9.4 \mathrm{~cm}$. Photo archive of the Cyril and Methodius National Library, Sofia, call no. C 507. 


\section{The Picture}

As is the case with the majority of Bulgarian historiography and illustrated literature, Kamenova's article contains no information on the portraits discussed. I cite this information here not only for the sake of completeness, but also because it is indispensable for a study of this kind. Information about the author, the place of origin and the date, the dimensions, the technique, and the present whereabouts - in short, the picture's provenance - will help to answer the question raised by Kamenova. At the same time, I will endeavour to carry out a formal analysis as well as a comparison of the two portraits discussed by Kamenova.

The portrait bust Kamenova published in her article, labelling it the "unreal photo of Benkovski” (fig. 1), is - in keeping with the newspaper printing technique of the time - black and white, and identifiable already at first sight as having been painted by hand. As we learn from the article by Zhechko Popov, who was to participate in the discussion sparked by Kamenova on the occasion of the hundredth anniversary of the April Uprising, the portrait was indeed painted - by Dragan Iliev in the year $1902 .{ }^{13}$ It depicts the bust of a man in three-quarter profile, gazing towards the right. His facial features are regular, and his hair thick, dark and slightly wavy, but carefully combed back to reveal the high brow and the slightly protruding, shapely ears. The gaze is earnest and direct, as is suggested by the dark eyes and the thin, well-formed eyebrows. The slightly curved contour of the full lower lip harmonises with the carefully shaped and slightly upward-curving dark moustache. The man, of young to medium age, wears a light-coloured shirt, the collar of which protrudes from under a dark vest. The black-and-white reproduction, and a bust portrait at that, allows neither the ascertainment of the subject's height nor of his skin colour, two features Kamenova includes in her description, possibly working from a colour reproduction of the portrait, or one coloured by hand at a later date.

The portrait of the young Benkovski that Kamenova identifies as "authentic" and "real" is captioned simply "Photo no. 3" in the article (fig. 2). This portrait is indeed a full-length photograph of a male figure resting his right arm on a decorative pedestal - a typical prop in the portrait studio of every professional photographer of the nineteenth century. The man, of young to medium age, wears a fez, a light-coloured shirt beneath a dark vest, a short, dark jacket (a saltamarka), pantaloons (potur in Turkish), a sash (around his waist), over which he has hooked his left thumb, lightcoloured stockings and dark shoes with small, pointed heels. Around his neck he wears a chain connected to a divit (Turkish for pen case) hanging demonstratively from his sash. Owing to its small dimensions in Kamenova's publication, the portrait does not permit a detailed description of the subject's facial features. Its wide circulation in historical and encyclopaedic literature, however, where it has frequently been

13 Popov 1976, p. 11. 
enlarged, and the personal inspection of the original, have simplified this task. ${ }^{14}$ The man's facial features are regular and his lips are full. He is posing in a three-quarter profile and looking towards the right. His short hair, neatly combed back beneath the fez, reveals the regularly formed and slightly protruding ears, while the eyes beneath the well-formed eyebrows are distinguished by a solemn, direct gaze. The faint dark contour above the upper lip is perhaps thin blond moustache, or possibly merely as a shadow.

Already at first sight, a formal comparison of the two portraits clearly reveals that the portrait bust which Kamenova claims does not show Benkovski was painted after the photo of the man Kamenova identifies as the young Benkovski. The doyen of the history of Bulgarian photography, Hristo Jonkov, comes to the same conclusion in his response to Kamenova's publication: "The portrait she [Kamenova] cites is a drawing, print, or the like, made after the only extant original photograph." 15 To explain the reasons for the author's "serious erroneous conclusions," her opponent continues the account by Madzharov:

For the festivities on the occasion of the twenty-fifth anniversary of the uprising and Benkovski's heroic death, the organisers needed his portrait. What they had at their disposal was the original, in which [...] Benkovski had been portrayed as a young man in 1868, i.e. eight years before the uprising, but with a fez. The fact that the beloved leader had been photographed with a fez, the symbol of the Bulgarians' submission to the Turks, wounded the initiators' pride and patriotic feelings. They therefore commissioned an artist to paint Benkovski after the photo, but without a fez. ${ }^{16}$

Jonkov goes on to say that it must have been difficult for an artist to know whether Benkovski had been blond or not from the photo. ${ }^{17}$ The artist had simply rendered Benkovski's eyes and hair darker, producing precisely the portrait whose authenticity Kamenova denies. Jonkov concludes his deliberations with a brief formal comparison of the two portraits:

Contrary to Comrade Kamenova, we must emphasise, however, that the portrait of Benkovski in question (the painted one) resembles the original [the photograph] extremely strongly. The oval shape of the face, the position of the head and the shirt are the same, as is the chain around the neck and the jacket; only the fez is missing.

14 The original is located in the photo archive of the Cyril and Methodius National Library in Sofia, call number C 507. I had the opportunity to examine it in October 2010.

15 Jonkov 1956, p. 3.

16 Ibid.

17 Here Jonkov makes passing reference to a special characteristic of early photography - the presumed capacity to reproduce reality faithfully (though not in colour). 
On the basis of this comparison, Jonkov comes to the conclusion that the painted portrait questioned by Kamenova "is a more or less well-wrought translation of the original into the drawing medium, but without a fez."18

The attempt undertaken by Zhechko Popov twenty years later to sum up the results of the debate in favour of Hristo Jonkov's line of reasoning essentially contributes little to the actual question of the 'authenticity'. On the contrary, the author resorts to Anna Kamenova's comparative method - this time, however, from a reverse perspective. According to Popov, the written descriptions by Zahari Stoyanov, Konstantin Velichkov and others, which he quotes in his article, "correspond perfectly with the photo of Benkovski [...] with the fez on his head," rendering "further comparisons unnecessary."19 The only new argument Popov contributes to the discussion in defence of the 'authentic' portrait is the silence of a number of Benkovski's friends and acquaintances with regard to this question. The author points out that the figures he has enumerated, every one of them proven revolutionaries and likewise nationally venerated heroic figures for example Stoyan Zaimov, Nikola Obretenov, Rayna Knyaginya and several others "would not have permitted a random person who had done nothing of merit to appear next to their portraits in place of the legendary Benkovski." ${ }^{20}$ In other words, except for Benkovski's nephew Michail Madzharov, all of the hero's comrades had confidently identified him in the photo. Otherwise they would have staunchly refused to allow the portrait to be included in the photo archive of national heroes or to be circulated. It is nevertheless remarkable that the author mentions neither Madzharov's opinion nor a statement uttered by Benkovski's sister about a certain Petar Zagorov in around 1899, who "could not inspect the likeness of Benkovski because the latter had unfortunately left no portrait of himself behind."21 Popov's contribution is rather of an art-historical nature, since he offers a well-founded survey of the abundant portrait production revolving around the figure of Benkovski, all of which is based entirely on the photo, except for the bronze bust of 1912 by Zheko Spiridonov in the Boris Garden in Sofia.

\section{The Text}

To date the discussion has revolved solely around the visual information conveyed by the portrait. The rest of the information it contains, above all in the form of handwritten and printed text on the back, has never been questioned and accordingly never been made a topic of discussion. It was Jonkov who first drew attention to the back of the photo when he cited its author, time and place of origin, and dimensions:

18 Ibid.

19 Popov 1976, p. 11.

20 Ibid., p. 12.

21 Zagorov 1899, p. 4. 
In this portrait measuring $6.5 \times 10 \mathrm{~cm}$, Benkovski was photographed by the famous photographer Pascal Sebah of Istanbul. [...] The style, the cardboard on which the photo is mounted, and the handwriting all point to the portrait's dating to before 1870 . Or, more precisely, 1868 can be considered the verified year of origin, as there is a dedication on the back that was written in pen and black ink. ${ }^{22}$

Popov's article likewise contains information on the provenance, which - very probably taken from Jonkov's article - he presents as being absolutely certain.

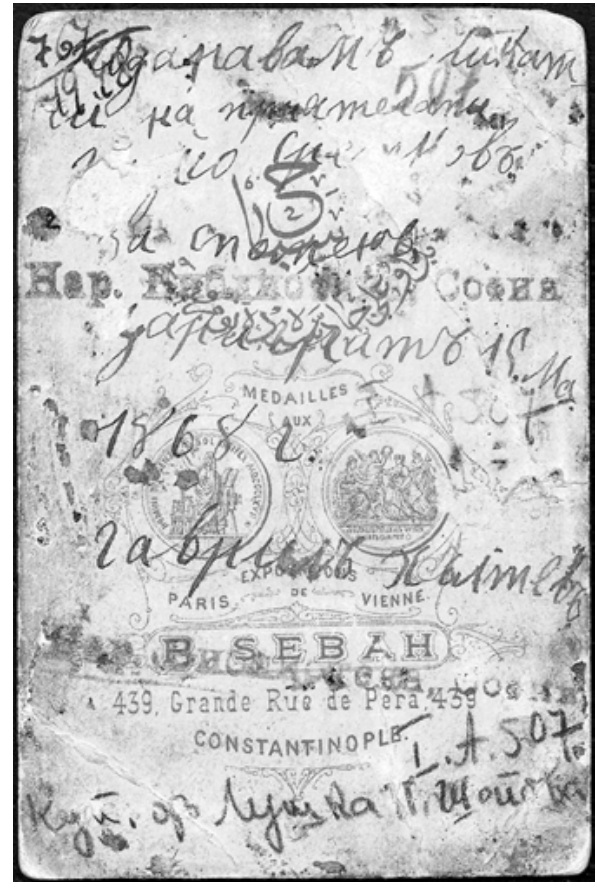

Fig. 3: Pascal Sebah: Anonymous photo prtrait of an Ottoman intellectual. Album print, calling card format, back, Istanbul after 1874.

Mounting board: $6.3 \times 9.6 \mathrm{~cm}$. Photo archive of the Cyril and Methodius National Libary, Sofia, call no. C 507.

It can indeed be gathered from the information on the back that the portrait was taken in the studio of Pascal Sebah, one of the most famous photographers of his time in the Ottoman capital (fig. 3). Sebah worked for several sultans, among them Abdul Hamid II, who was himself known as an amateur photographer and as one of the greatest promoters of photography in $19^{\text {th }}$ century. The portrait print measures $5.3 \mathrm{by} 9.4 \mathrm{~cm}$, the cardboard backing 6.3 by $9.6 \mathrm{~cm}$. As was usual for carte de visite photos, the back of the photo - which also served as an advertising medium for the photo studio - contains information about Sebah's establishment. In addition to this information, which will be discussed in detail below, the back contains the stamps of the photo archive,

22 Jonkov 1956, p. 3. 
applied later, and numerous handwritten memos by archivists. Undoubtedly the most important of the latter, and presumably for that reason the only one to be mentioned in the discussion, is Benkovski's handwritten dedication. The usual text encountered on such portraits, it reads as follows: "I give my portrait to my friend [name illegible]. Carigrad [Istanbul], 19 May 1868, Gavril Hlatev.” The photo, in other words, is a classical photo portrait in carte de visite format dating from the second half of the nineteenth century, originating in Istanbul in the studio of Pascal Sebah in 1868, and was given or at least intended - as a gift to a friend whose name is not known.

At first sight, this information seems to make sense. It also seems logical in view of Benkovski's biography, even if the latter is shrouded in mystery up until 1875 - the year of his emigration to Romania and one year before his death - since everything known about it is based on hypothesis and information conveyed by word of mouth. Or, as the most important chronicler of the April Uprising of 1876 and Benkovski companion Zahari Stoyanov writes, "Georgi Benkovski emigrated to Romania, known to nobody until that time." ${ }^{23}$ Not even his date of birth has come down to us.

Born in Koprivshtica (present-day Bulgaria), presumably between 1841 and 1844, Benkovski is thought to have attended school for three years before departing for Asia Minor at the age of about sixteen. In the Anatolian cities of Denizli, Uşak, Aydin, Eski Şehir and Istanbul, he was allegedly active as a tradesman until $1875 .{ }^{24}$ He verifiably visited the Ottoman capital again in the autumn of 1875 with a group of Bulgarian migrants from Romania, with the aim of setting fires at strategic locations in the city an undertaking which, as we know, failed, not least thanks to good work on the part of the Ottoman police. This stay in Istanbul also marks Benkovski's last meeting with his nephew, Michail Madzharov, who was attending the prestigious Robert College at the time, and who would later write in his Memories that the portrait was not of Benkovski.

The dedication on the back of the photo indicates that Benkovski must already have visited the Ottoman capital in 1868, and had himself been photographed by Pascal Sebah. Apart from Istanbul, Eski Şehir is the only city in which Benkovski according to the evidence - lived or sojourned before going into exile in Romania. The same applies to the dates of his travels. Until his emigration in 1875, we are informed only of two dates on which Benkovski spent time outside his native Koprivshtica 1866 in Eski Şehir, where he was the business partner of a certain Hrelkov, whose wife would later supply the photo, and 1868 in Istanbul. Apart from the photo, two written documents relating to Benkovski and providing information about his stays abroad

23 Stoyanov 1933, p. 188.

24 Benkovski's biography is based primarily on information passed down orally. Apart from the two documents cited below and a small number of official Ottoman police documents which, in keeping with their function, contain precise descriptions of the wanted man's outward appearance, there are no written sources whatsoever. The biographical information cited here was drawn from one of the few relatively straightforward descriptions of Benkovski’s life: Strashimirov 1907, vol. 1, pp. $235 \mathrm{ff}$. 
have come down to us. The first is a credit token for eight Turkish lira, which Benkovski received from his uncle, Michail Madzharov's father, and which he signed in Koprivshtica in 1866, apparently right before leaving for Asia Minor to seek his fortune as a merchant. The second is a letter from Benkovski to his creditor, written in the Anatolian city of Eski Şehir and likewise dating from 1866. In it he writes that he will not be able to pay the loan back that year because he has not yet earned enough money. Kamenova publishes a facsimile of the credit token in her article, commenting that we thus finally have at our disposal a document bearing Benkovski's handwriting and signature (fig. 4).

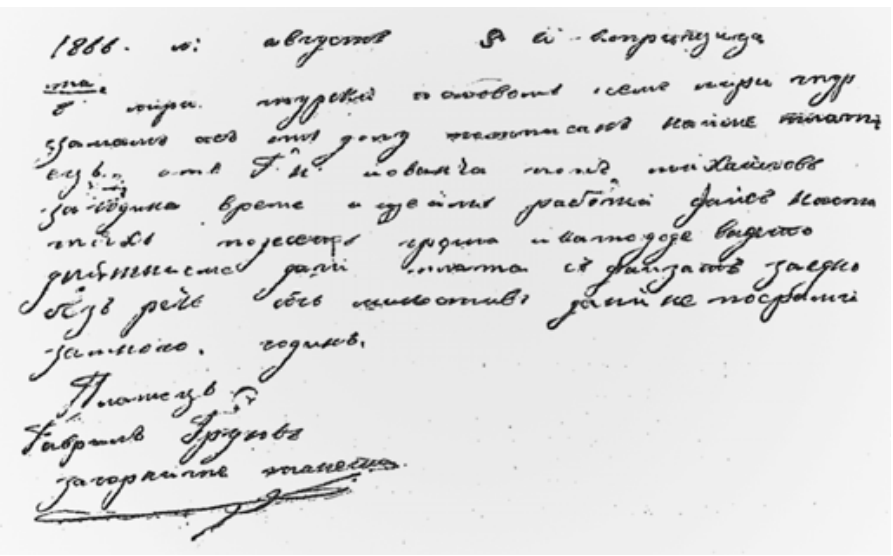

Fig. 4: Credit token in the name of Gavril Grujov (Georgi Benkovski), issued in Koprivshtica, August 1866. Photomechanical reproduction from: Anna Kamenova, "Obrazat na Benkovski," in: Literaturen front, 18, 3 May 1956.

A comparison of the handwriting on the photo and that on the credit token, however, reveals great stylistic differences. Whereas the credit token exhibits a neat, even, almost elegant handwriting style, the dedication on the photo was undoubtedly set down by a different, less practised, and very uneven hand. The latter corresponds to the description of Benkovski's handwriting by Michail Madzharov, according to whom his uncle "could speak incomparably better than he could write; his writing was irregular and he made a lot of grammar mistakes." ${ }^{25}$ It is very likely that it was not Benkovski himself but someone else who wrote and signed the credit token, presumably because this other person had better handwriting.

25 Madzharov 1968, p. 308. 


\section{The Front}

In this context there arises another question of no less importance for the identification of the person in the photo. It is related to the attribute demonstratively displayed hanging from the sash around the subject's waist - a divit. The latter was a kind of pen case with two compartments, one for a pen and one for ink. In the Ottoman cultural world, the members (mostly male) of the educated class always wore the divit conspicuously on their belts, not only as a working utensil kept always close at hand, but also as a symbol of intellectual activity, education and mastery of calligraphy. A large number of portraits of educated Ottomans depicted with divits on their belts have come down to us. Our portrait obviously adheres to this iconographic tradition, its subject having presumably attached high importance to being shown as a member of the educated class, or, in other words, as an intellectual.

This observation, however, is diametrically opposed to the image of the national hero that we have from written sources, and to which his contemporaries testified in many cases. Here we will confine ourselves to a few examples from Zahari Stoyanov's Chronicle, which indicates that Benkovski at no time considered himself an intellectual, but on the contrary had a strong aversion to educated people: "I am glad" Stoyanov quotes the words spoken by his comrade-in-arms Benkovski at their first meeting - "that there are no grammars or commas roving about in your [Stoyanov's] head." "26 There is also the story of the conflict between Benkovski and the head of the Revolutionary Committee, Panayot Volov, arising from Benkovski's avowed antipathy towards the educated Volov: "Volov bungled everything with his grammar - Benkovski cried, beside himself, after receiving a letter full of poetry." And: "Benkovski hated all more or less educated people, but first and foremost Volov." ${ }^{27}$ A final quotation from Stoyanov suffices to attest Benkovski's attitude towards education and well-formed handwriting:

\footnotetext{
It was Volov and Bobekov whom Benkovski attacked most frequently - the former was a grammar school pupil in Russia, the latter at the Istanbul School of Medicine. He called them grammarians and philosophers and told them openly to their faces that grammar and gunpowder had nothing in common. To express his distaste for this class of people, he ignored all letters that had been written in calligraphic handwriting. ${ }^{28}$
}

These written descriptions and the photograph's visual message are completely at odds with one another. It seems highly unlikely that a person who abhorred beautiful handwriting should have himself portrayed with the quintessential attribute of calligraphy, the divit. Yet even if we were to assume that Benkovski may have cherished

26 Stoyanov 1933, p. 244.

27 Ibid., p. 259.

28 Ibid, p. 264. 
intellectual ambitions in 1868, when the photo was dedicated, and even if the irreconcilability of the rather clumsy writing on the back of the photo and the divit as a symbol on the front does not provide us with a reliable basis for an answer to our question, there is another much more significant problem, one resulting not so much from the handwriting style but from the date of the dedication and the dating of the photograph. On the basis of the dedication, it is unanimously assumed that the photograph was taken in 1868, leading in turn to the conclusion that 1868 was the year in which Benkovski first visited Istanbul for the first time. According to Dimitar Strashimirov, however, who, as already mentioned, was the first to publish the photo, "the portrait of Benkovski dates from the year 1862 and was made in Istanbul."29 If Strashimirov is correct, the photo was not taken in 1868, as suggested by the dedication, but six years earlier, in 1862 .

\section{The Back}

Whether the date in Strashimirov's book is a misprint that turned "1868" into "1862," or whether in 1907, the year the book was published, the portrait still bore no dedication certifying the photo's date, is an important question hitherto not raised in the discussion. It had, however, been alluded to. "Even if we were to question the authenticity of the dedication" - Hristo Jonkov writes - "there is no reason to doubt this youthful portrait of Benkovski." ${ }^{30}$ Unfortunately, Jonkov does not explain why he doubts the authenticity of the dedication, but whatever the reason, it was very probably what led him to set the date of the portrait rather vaguely at "before 1870." 31

The reasons for Jonkov's doubts can be clarified solely with the aid of the advertising information on the back of the picture, and thus with the aid of information about the photographer Pascal Sebah's studio. Sebah opened his studio in Tom-Tom Street in Istanbul in 1857, “opposite the Austrian postal station," and moved to a location in the capital's most prominent street, the Grande Rue de Pera (number 439), next to the Russian embassy, in around 1868. This we know from the addresses found on the mounts Sebah used for his portrait photos. In 1873, having come to great fame not only in the Ottoman Empire - after all, he worked for the sultan - but also in Europe and the United States, Sebah opened a branch in Cairo. ${ }^{32} \mathrm{He}$ was awarded a number of distinctions, for example at the photo exhibitions in Paris and the world

29 Strashimirov 1907, p. 236.

30 Jonkov 1956, p. 3.

31 Ibid.

32 On the life and work of Pascal Sebah, see for example Öztuncay 2003, pp. 259-81; Çizgen 1995, pp. 78-89. On his role as court photographer and the historical context, see Baleva 2012a, pp. $273-94$. 


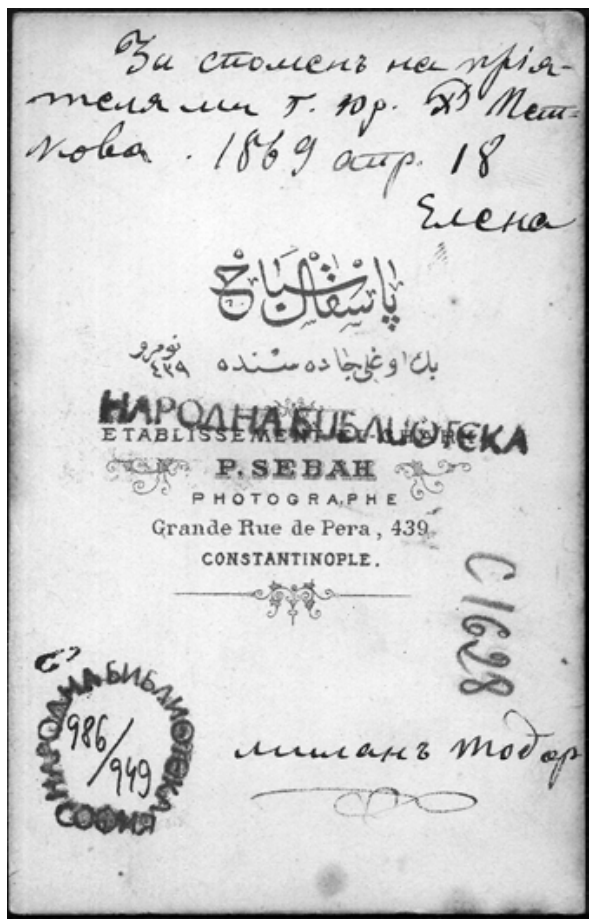

Fig. 5: Pascal Sebah: Photo portrait of Milan Todor[ov]. Albumen print, calling card format, back, Istanbul 18 April 1869. Mounting board: $6.6 \times 10.3 \mathrm{~cm}$. Photo archive of the Cyril and Methodius National Library, Sofia, call no. C 1628.

fairs in Vienna and Philadelphia, as well as the highest distinction of the empire, the Order of Osmanieh, presented to him by Sultan Abdülaziz in 1874. This information is important for answering the question whether or not the portrait is of Benkovski. In fact, it is the only means of arriving at a definitive answer.

In the nineteenth century, distinctions in the form of medals and deeds not only brought honour and fame to any commercial photo studio, but were also important for advertising. Every distinction, whether a medal or a certificate, was reproduced on the back of the photo mounts shortly after its presentation, thus increasing the prestige not only of the photographer, but also of the people that he photographed. The more distinctions a studio had received, the more expensive it was, the wealthier the customers who had themselves were being portrayed there and - most importantly for the historian - the more precisely can its production be dated. In the case of Sebah, we are very fortunate in this respect, because from 1870 until his death he received a distinction every two years on average, and the distinction always appeared on the backs of the cardboard mounts a short time later. Before Sebah received his first distinction in 1870 at the exhibition of the Société française de photographie in Paris, the mounts were white with nothing but the address of the studio printed on them in black. The photographic likeness of Milan Todorov, produced when he was studying in Istanbul, signed by him personally, and dating with all certainty from the year 

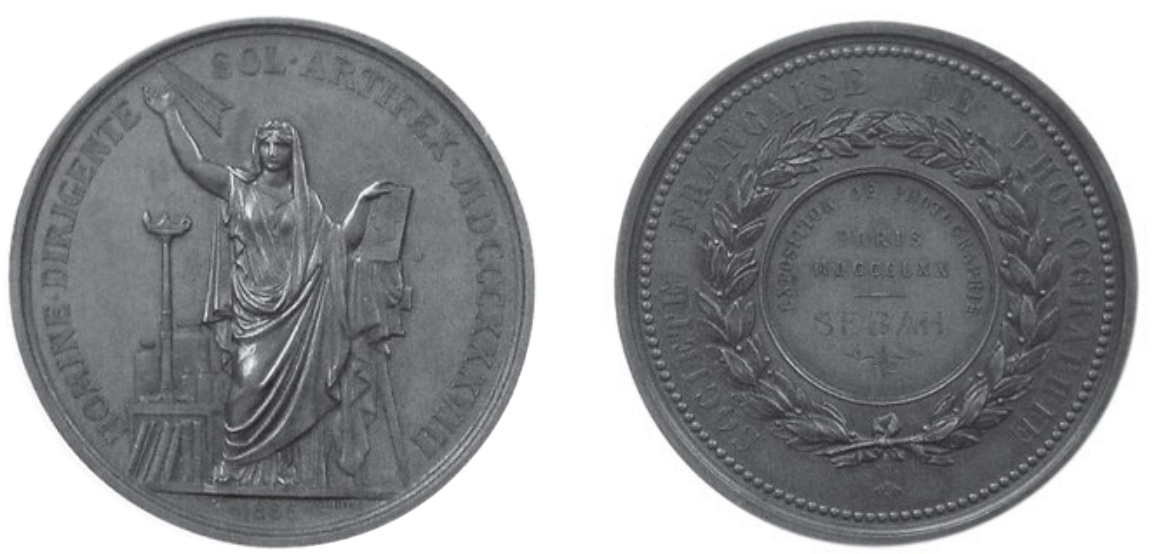

Fig. 6: Bronze medal of the Société française de photographie, engraved with the name Pascal Sebah, 1870, Paris, design: Eugène-André Oudiné, 1866, Pierre de Gigord Collection. Photomechanical reproduction from: Bahattin Öztuncay, The Photographers of Constantinople. Pioneers, Studios and Artists from 19th-Century Istanbul, Istanbul 2003, vol. 1, p. 266.

1869, was taken by Pascal Sebah (fig. 5). ${ }^{33}$ All that appears on the back of the mount is the address of the studio in Latin letters, and an advertising slogan in Arabic with the usual rhetoric of early photographic studios. Other well-preserved and unequivocally dated calling card portraits of the 1860 s by Sebah feature similar mounts.

The portrait of Benkovski, on the other hand, which on the basis of the findings discussed so far would have to date from between 1862 and 1868, is mounted on a backing of an entirely different design. It is yellowish in colour and the information about the studio now appears in red. These are the colours Sebah would retain until the end of his life. What is more, the mount now not only features the name and address of the studio, but also two medals, reproduced in the most conspicuous place, the centre. The medal on the left is from the Paris exhibition and bears the clearly discernible date 1870 in Roman numerals as well as the name of the prize's recipient, Sebah (fig. 6). The photographer received the one on the right at the world fair in Vienna for his album containing photos of all of the peoples living in the Ottoman Empire, a volume that was already very famous at the time. ${ }^{34}$ The fair took place in 1873, and by 1874 the Viennese medal was to be found on the Sebah photo mounts (fig. 7).

33 The well-preserved original is located in the Cyril and Methodius National Library in Sofia, call number C 1628.

34 The volume, entitled Les costumes populaires de la Turquie en 1873 and illustrated with seventyfour phototypes, was published in Istanbul in 1873 for the Vienna World Fair by, among others, the most prominent Ottoman painter of the time, Osman Hamdi Bey. 

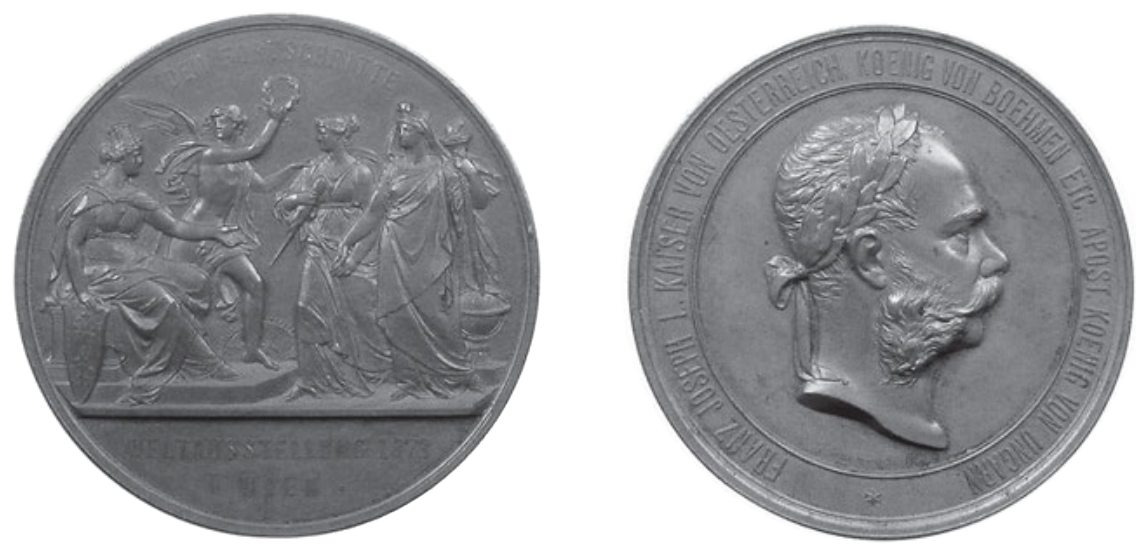

Fig. 7: Medal of Progress awarded at the Viennese World Fair of 1873, design: Josef Tautenhayn, c. 1873. Photomechanical reproduction from: Bahattin Öztuncay, The Photographers of Constantinople. Pioneers, Studios and Artists from 19th-Century Istanbul, Istanbul 2003, vol. 1, p. 268.

This finding permits us to raise justifiable doubts about the dating of the photo, hitherto considered accurate. Among other things, it poses the question as to why a mount dating from 1874 could have been used for a photo taken in 1868. Older mounts are known to have been used by such photo studios, including Sebah's, for photographs of later dates. However, we have never yet encountered the reverse instance, i.e. the use of a new mount for a photograph of an earlier date. Yet even if we were to assume that the subject of the photograph really is Benkovski - who, however, to judge from all of the findings gathered here could not have had himself photographed before 1874 - it would hardly make sense for him to have predated a portrait intended for a friend by six years. We must concede that there is no logical explanation for such an inscription. On the contrary, it is to be assumed that the photographic portrait of an anonymous and presumably well-educated young man only received its inscription at a later date as a means of awarding the unknown Ottoman intellectual on the photo the identity of the well-known Bulgarian revolutionary as desired and undisputed by Bulgarian historiography.

\section{Conclusion}

In view of all of the arguments and facts cited here, the photo portrait is presumably not a portrait of Benkovski. The only means of identifying the national hero in this photographic likeness is by adhering to the historiographic methods and intentions exposed here with the aid of source-critical pictorial analysis. If we were to follow this historiographic example, it would be entirely conceivable that the photograph actually 
was taken on one of those fateful days in the autumn of 1875 when Benkovski is known to have set out for Istanbul with a small group of Bulgarian emigrants to set fires at certain strategic locations in the city. As we know from the memories of his comrades likewise involved in the undertaking, but also from the Ottoman files on the case, the plot was detected by the Ottoman police at an early stage and nipped in the bud. Benkovski, or Gavril Hlatev, who was in Istanbul illegally at the time, left the city rapidly with the identification card of a certain Polish emigrant by the name of Antoni Benkovski. The Bulgarian emigrant adopted the Pole's surname for his own, and within a few years it had become a symbol of Bulgarian bravery and willpower. Significantly, the national hero went down in history with this - and not his real - name.

The bravery and willpower of Gavril Hlatev, alias Georgi Benkovski, today constitute one of the undisputed historical truths of national historiography. These officially sanctioned qualities could readily deceive one into thinking - and I here take the liberty of elaborating on the heroic story in the spirit of the national idea - that a hero like Benkovski would by all means have been capable of making and keeping an appointment with the Ottoman court photographer, whose studio was located in the most well-known and safest street in town, while the police were hunting for the conspirator far and wide. Bravery and willpower, however, do not suffice to explain why the front of the photographic portrait shows an Ottoman intellectual. An analysis of Benkovski's intellectual side - a side hitherto ignored by historiography - could accordingly be a project for future research. If the historians would have us accept this hitherto unknown characteristic of the national hero, however, they will have to present us with well-founded scholarly arguments - naturally, only in the event that they do not agree with the conclusion that the photographic portrait of the 'Bulgarian national hero' is a construct of the national archive that has never been anything but untenable.

\section{Bibliography}

Baleva 2012: Martina Baleva, “Obrazat na Benkovski. V lice i v grab” [The portrait of Georgi Benkovski: front and back views], in: Kultura Weekly, 18 (2680), 11 May 2012, pp. 6-7.

Baleva 2012a: Martina Baleva, "The Empire Strikes Back: Image Battles and Image Frontlines during the Russo-Turkish War of 1877-1878," in: Ethnologia Balkanica, 16, 2012, pp. 273-94.

Bertillon 1895: Alphonse Bertillon, Das anthropometrische Signalement. Zweite vermehrte Auflage mit einem Album, ed. by Ernst von Sury, 2 vols., Bern et al. 1895.

Çizgen 1995: Engin Çizgen, Photography in the Ottoman Empire. 1839-1919, Istanbul 1995.

Hamdi Bey et al. 1873: Osman Hamdi Bey/Marie de Launay/Pascal Sebah, Les costumes populaires de la Turquie en 1873. Ouvrage publié sous le patronage de la Commission impériale ottomane pour l'Exposition universelle de Vienne (1873), Constantinople 1873.

Jonkov 1956: Hristo Jonkov, "Za portreta na Benkovski” [On the portrait of Benkovski], in: Narodna mladezh, 180, 28 July 1956, p. 3.

Kamenova 1956: Anna Kamenova, “Obrazat na Benkovski” [The portrait of Benkovski], in: Literaturen front, 18, 3 May 1956, front page. 
Madzharov 1968: Michail Madzharov, Spomeni [Memories], ed. by Vesselin Andreev, Sofia 1968. Öztuncay 2003: Bahattin Öztuncay, The Photographers of Constantinople. Pioneers, Studios and Artists from $19^{\text {th }}$ Century, 2 vols., Istanbul 2003.

Popov 1976: Zhechko Popov, “Istinski li e portretat na Benkovski?” [Is the portrait of Benkovski authentic?], in: Otečestvo, 4, 20 February 1976, pp. 10-12.

Stoyanov 1933: Zahari Stoyanov, Zapiski po balgarskite vastaniya. Razkaz na ochevidci, 1870-1876 [Notes on the Bulgarian uprisings: told according to eyewitness accounts, 1870-1876], Sofia 1933.

Strashimirov 1907: Dimitar Strashimirov, Istorija na Aprilskoto vazstanie [History of the April Uprising], 3 vols., Sofia 1907.

Zagorov 1899: Petar Iv. Zagorov, Edno poseshtenie na istoricheskata Koprivshtica [A visit to the historical city of Koprivshtica], Sofia 1899. 